\title{
Considerations of Public Security Traffic Big Data Platform Integrated Application under the Coordinated Region Development
}

\author{
$\mathrm{Xu} \mathrm{Xu^{1,2,a } \text { , Ying Wang }}{ }^{3, b}$ and Jin Deng ${ }^{3, c}$ \\ ${ }^{1}$ Third Institute of Ministry of Public Security, No.339 Rd.Bisheng, Shanghai, China \\ ${ }^{2}$ Public Security Department of Tibet Autonomous Region, No.26 Rd.Linkuo, Lasa,China \\ ${ }^{3}$ Beijing Traffic Management Bureau, No.1 Rd.Fuchengmen, Beijing,China \\ aforxuxu@126.com, ${ }^{b}$ wangyingbit@126.com, ${ }^{c}$ shuyu_731@126.com
}

\begin{abstract}
Keywords: big data, traffic management.
Abstract. Under the coordinated development of Beijing-Tianjin-Hebei, accurately grasping of the feature, conception and method of big data is important to improve traffic service in the new height and starting point. By experienced and theoretically analyzing, the enhanced reliability is considered to be the combined results of the problem configurations and the depressed related influence.
\end{abstract}

\section{Introduction}

By the end of 2015, the amount of vehicle is 23.05 million, the amount of driver is 30.66 million in Beijing-Tianjin-Hebei region, and maintain sustained growth. With the boost of national strategy on coordinated development of Beijing-Tianjin-Hebei region, the relationship will further strengthen. The contradiction between strong traffic demands and resources environment rigid constraint becomes more prominent.

With the supports of government, Beijing-Tianjin-Hebei region has built the signal controlling, video surveillance, traffic flow collection, traffic information release and audit monitor systems after years of efforts. It also has built up the traffic big data resources of people, vehicles, roads, environment and so on. Accurately grasp the characteristics of the era of big data, in-depth analysis of the influence in the public management, which is very important to improve traffic conditions of Beijing-Tianjin-Hebei region in the new height and starting point.

\section{Problems Analysis}

Although Beijing-Tianjin-Hebei region has accumulated traffic data resources, the preparation is still inadequate of new technology and application on traffic management. The main existing problems as followings:

1.The systems of three provinces make great difference, and the standardization of the Beijing-Tianjin-Hebei lag behind. Public security traffic science and technology system of Beijing-Tianjin-Hebei region has characteristics of period distribution and different technical condition. Different region with different systems and most of which are keep constructing and consummating while using. Significant difference on data content, data format, data quality, logical model and management model, lack of unified standard on a large number of application, will be the fundamental obstacle on the underlying data interconnection and sharing. Urgent needs to improve the interface specification and standard system of science \& technology system which lay the foundation of depth usage and mining of cross- region and cross-period traffic management big data.

2. Public security traffic data application is still in its primary stage, and comprehensively deepen application is imminent.

Although each region has big date resources of people, vehicles, roads, environment, law enforcement and others, only very few traffic big data has been analyzed and mined because of the data source diversity, rich types and low correlation degree. Some of unstructured data which occupy vast resources such as document images, monitoring audio and video is very difficult to effectively use. As the results, overall level of collaborative transformation lag behind. It is urgent needed to meet big data 
architecture to guide the work and built up the traffic management model through the depth of data mining, research and analyze.

3. Lack of emergency management mechanism based on regional collaboration, it is still has long way to go.

Based on the big data analysis and information sharing, the stabilizing ability to the suspect vehicles and key person is obviously insufficient.Lack of regional collaborative emergency management mechanism, the prediction and warning on traffic congestion, serious accidents or other emergencies still need to be enhanced. It is urgently needed to improve the public security traffic police command and control ability.

4. Information security and privacy protection still needs the attention.

In the situation of big data sharing, opening and social utilization, the traffic data resources will no longer be limited to internal use. Traffic big data applications change the characteristics of data security risks, not only need a new management method, also, introduction of comprehensive risk management system, unification of monitoring and management is necessary. How to regularize the release range of traffic big data, available content of data, privacy processing for specification and so on, how to ensure information security and privacy, effectively protect the personal information, business information in the open environment, avoid malicious damage, all will be the major problem of public security traffic administration need to break through.

Table 1. Big data application problem analysis in Beijing-Tianjin-Hebei region

\begin{tabular}{l|l|l}
\hline \multicolumn{1}{c|}{ Problems } & \multicolumn{1}{c}{ Influences } & \multicolumn{1}{c}{ Solutions } \\
\hline $\begin{array}{l}\text { System } \\
\text { differences }\end{array}$ & $\begin{array}{l}\text { Data content and quality difference } \\
\text { Lack of support between systems } \\
\text { interconnection and collaboration }\end{array}$ & $\begin{array}{l}\text { Top-level design } \\
\text { Overall plan and coordination }\end{array}$ \\
\hline $\begin{array}{l}\text { Out-dated } \\
\text { systems }\end{array}$ & $\begin{array}{l}\text { Basic technical barriers } \\
\text { Platform integration is difficult }\end{array}$ & $\begin{array}{l}\text { Regularize regional standards } \\
\text { system interface }\end{array}$ \\
\hline $\begin{array}{l}\text { Primary } \\
\text { applications }\end{array}$ & $\begin{array}{l}\text { Value of police data has not been fully } \\
\text { excavated and transformed }\end{array}$ & $\begin{array}{l}\text { Research new technology and } \\
\text { new method } \\
\text { Deepen the application }\end{array}$ \\
\hline $\begin{array}{l}\text { Emergency } \\
\text { management }\end{array}$ & $\begin{array}{l}\text { Insufficient ability of anti-terrorism } \\
\text { and emergency forecast and } \\
\text { treatment }\end{array}$ & $\begin{array}{l}\text { Big data information transfer } \\
\text { Information and plan auxiliary }\end{array}$ \\
\hline $\begin{array}{l}\text { Information } \\
\text { security }\end{array}$ & $\begin{array}{l}\text { Data open content, privacy processing } \\
\text { and protection on scope of data }\end{array}$ & $\begin{array}{l}\text { Risk management system } \\
\text { Regulation system }\end{array}$ \\
\hline
\end{tabular}

\section{Project Design}

1.To carry out the top-level design of big data integration application.

As a new stage of development of intelligent transportation, the traffic data has been greatly liberated in terms of breadth of data acquisition, depth of interaction and richness of application and development. At the same time, the development of traffic data has characteristics of distinct phase, exploratory, applications locality, scattered and small-scale.

With the establishment of information security and regulations system, it is possible to provide solid legal protection for big data application.

The demand of top-level design of regional traffic data management is not only from Beijing-Tianjin-Hebei region, but also from national focus. It will be a good demonstration for other region to achieve data sharing and comprehensive application.

2.Design the standardized mechanism of information gathering, transformation and releasing. 
In view of the differences in contents, forms and utilization patterns of traffic big data, the preparation of new technology and new application of intelligence transformation in new environment is still insufficient. Focus on vehicles in the field of public security, it is the first step to establish the standardized mechanism of intelligence transformation on the basis of analysis of intelligence service. Using Hadoop architecture of HDFS distributed file system, it is very effective to accomplish data storage, accomplish the data clean, data compensation and data fusion. Under the framework of Map/Reduce, Spark, HANA memory computing, it will achieve high performance to realize multi-source heterogeneous traffic intelligence of big data, cooperate with the backend storage management and information resources sharing platform, cooperation and association information fusion processing platform. Through the high-quality intelligence service to enhance the level of public management and emergency response capability, it is practical to achieve the mechanism of long-term sharing and utilization, promoting regional police intelligence collaborative service.

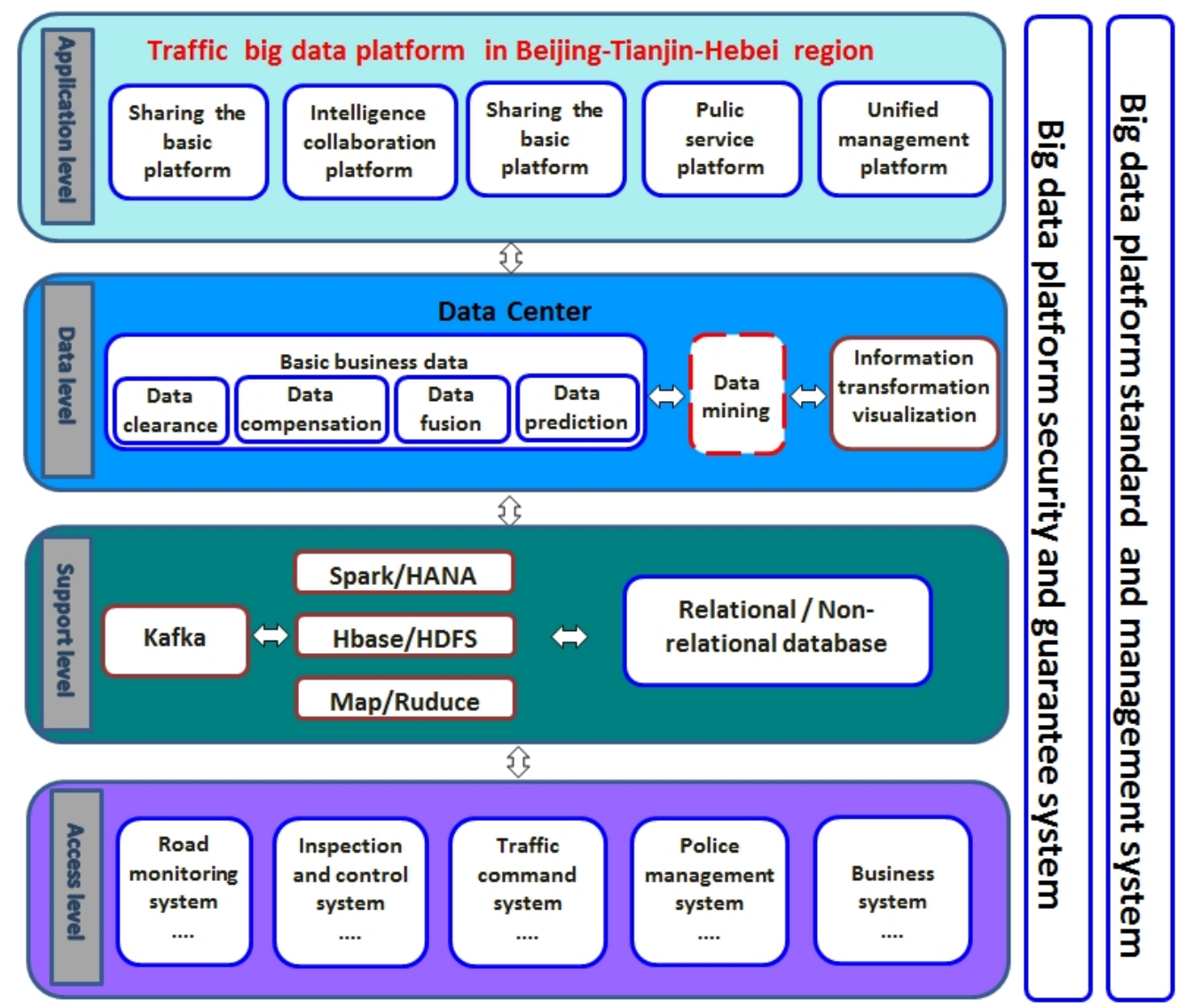

Fig.1 The technical frame of traffic big data platform

3. Research and development of the trend prediction of main traffic work .

Combined the data association analysis technology and special knowledge to establish a deep link between people, vehicles, roads and environment, it will be the first time to respond for the change of the total traffic demand, composition, spatial and temporal distribution which caused by evacuation and rescue, further to guide traffic control department.

4.Improve the effectiveness of plan evaluation and decision support.

The management of traffic plan is relatively extensive, including comprehensive consideration of control target, resource constrains, and security, etc. However the manual plans are relatively fixed, low variable and adaptable, it is needed to improve the pertinence and effectiveness for different traffic subject, traffic region, the traffic control time. According to the requirements of traffic organization and the characteristics of traffic flow, it should be comprehensively considered by the system level of the regional traffic impact, the decision support of beforehand assessment, in process monitoring, and afterwards evaluation. 
5.Interregional shared linkage, deepen and rich traffic internal business support service.

Under the platform of traffic big data, the data collection and integration of traffic management in Beijing-Tianjin-Hebei region will be strengthened. It will be friendly to manage the traffic data resource in unified platform instead of in various systems previously. And it also will promote the data sharing application between different departments according to the different requirements. Using the key technology of depth learning, high performance computing, theme model, multi-dimensional analysis and visualization, it will achieve a wide range of emergency consultation, joint command and dispatch, emergency dispatch, work transfer and other coordination mechanisms to strengthen the Beijing-Tianjin-Hebei region comprehensive management and control of traffic capabilities. 6.Break the regional restriction, innovate the traffic management service.

According to the demands of different groups, the traffic service will be providen through web, APP, SMS, voice calls and other ways, including driving test, vehicles inspection appointment, car license and plate, illegal processing and penalty, travel information, information query, notification prompt, information disclosure and so on.

\section{Conclusions}

Aiming at the requirements of safety development and accident prevention, the new technology and conception of big data have been comprehensively used to break through the technical bottlenecks of public security traffic management. With the integration management of the practical needs of the traffic data, it is expectable to achieve the environmental-friendly regional collaborative development.

\section{Acknowledgements}

This work was financially supported by Science Technology Foundation of Beijing (Z141100002714003, Z151100002115041), Key Research Program of Ministry of Public Security(No.201302ZDY017), National Development and Reform Commission and Department of Science and Technology of Tibet Autonomous Region.

\section{References}

[1] Xiaolong Jin, Benjamin W.Wah, Xueqi Cheng, Yuanzhuo Wang, Significance and Challenges of Big Data Research, Big Data Research, February 2015

[2] HanLi Wang et al.Large-scale Multimedia Data Mining Using MapReduce Framework, International Conference on Cloud Computing Technology and Science,2012

[3] Jeffrey Dean and SanjayGhemawat, MapReduce: Simplified Data Processing on Large Clusters. in proc,OSDI,2004

[4] Apache Hadoop,http://hadoop.apache.org/core 